Revista Nacional de

Gerenciamento de Cidades

\title{
RCC - RESÍDUOS DA CONSTRUÇÃO CIVIL: CARACTERIZAÇÃO DE SUA GESTÃO INTEGRADA
}

\author{
Rodrigo Cordeiro da Silva ${ }^{1}$
}

Krystal de Alcantara Notaro ${ }^{2}$

\begin{abstract}
RESUMO O Conselho Nacional do Meio Ambiente - CONAMA em suas atribuições estabelece diretrizes, critérios e procedimentos para a gestão de resíduos sólidos da construção civil. Tal administração possibilita uma política ambiental ampla e eficaz, que objetiva alcançar, estabelecer e organizar a não geração, a redução, a reutilização, a reciclagem e o destino final dos materiais deixados do processo de construção. De uma forma plural, as resoluções do CONAMA tem alcançado uma política de gerenciamento satisfatória, mesmo enfrentando dificuldades. $O$ não interesse dos setores públicos, seja ele público ou privado, para essa política dificulta o cumprimento pleno dessa resolução. Nesse contexto, o presente trabalho objetiva levar ao meio acadêmico e científico discussões no tocante dos Resíduos da Construção Civil - RCC. Entre os inúmeros aspectos que foram analisados, fica em evidência a necessidade de existência de uma gestão desses materiais. Tendo em vista que esses setores devem traçar metas, que cumpridas, minimizam os impactos ao meio ambiente, potencializando a produtividade da indústria da Engenharia Civil e consequentemente seus lucros, priorizando uma política ecologicamente correta.
\end{abstract}

PALAVRAS-CHAVE: Gestão de Resíduos, Políticas Públicas, Meio Ambiente, Sustentabilidade.

\section{RCC - WASTE OF CONSTRUCTION: CHARACTERISTICS OF THEIR INTEGRATED MANAGEMENT}

\footnotetext{
${ }^{1}$ Graduando de Bacharelado em Engenharia Civil, Autarquia do Ensino Superior de Garanhuns AEGA/Faculdade de Ciências Exatas de Garanhuns - FACEG. cordeirorodrigo13@hotmail.com.

${ }^{2}$ Profa ${ }^{2}$ M.s Krystal de Alcântara Notaro, Autarquia do Ensino Superior de Garanhuns AEGA/Faculdade de Ciências Exatas de Garanhuns - FACEG. krystal.notaro@gmail.com.
} 


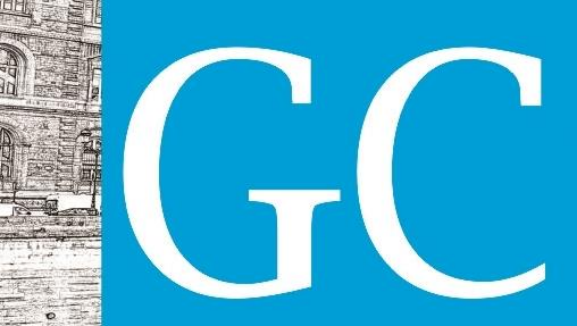

Revista Nacional de

Gerenciamento de Cidades

SUMMARY The National Environmental Council - CONAMA on their assignments establishes guidelines, criteria and procedures for the management of solid waste construction. Such an administration enables a comprehensive and effective environmental policy, which aims to achieve, establish and organize non-generation, reduction, reuse, recycling and final disposal of materials left the building process. A plural form, the resolutions of CONAMA has achieved a satisfactory management policy, even facing difficulties. Non-interest public sectors, whether public or private, to this policy hinders the full implementation of that resolution. In this context, this paper aims to bring the academic and scientific community discussions regarding Waste Construction - RCC. Among the many aspects that were analyzed, it is in highlighting the need for existence of a management of these materials. Given that these sectors should set goals, which met, minimizing environmental impacts, increasing the Civil Engineering industry productivity and hence profits, prioritizing an environmentally friendly policy.

KEY-WORDS: Waste Management, Public Policies, Environment, Sustainability.

\section{RCC - RESIDUOS DE CONSTRUCCIÓN: CARACTERÍSTICAS DE SU GESTIÓN INTEGRADA}

RESUMEN El Consejo Nacional del Ambiente - CONAMA en sus tareas establece directrices, criterios y procedimientos para la gestión de la construcción de los residuos sólidos. Dicha administración permite una política ambiental integral y eficaz, que tiene como objetivo lograr, establecer y organizar la no generación, reducción, reutilización, reciclaje y disposición final de materiales dejado el proceso de construcción. Una forma plural, las resoluciones de la CONAMA ha logrado una política de gestión satisfactoria, aunque con dificultades. Sector público no vinculados con intereses, ya sea pública o privada, a esta política dificulta la plena aplicación de esa resolución. En este contexto, el presente trabajo pretende acercar las discusiones de la comunidad académica y científica en materia de residuos de la construcción - RCC. Entre los muchos aspectos que se analizaron, es poner de relieve la necesidad de la existencia de una gestión de estos materiales. Dado que estos sectores deben establecer metas, que se reunió, minimizando los impactos ambientales, aumentando la productividad de la industria de Ingeniería Civil y por lo tanto los beneficios, priorizando una política de medio ambiente.

PALABRAS CLAVE: Gestión de Residuos, Políticas Públicas, Medio Ambiente, Sostenibilidad. 
Revista Nacional de

Gerenciamento de Cidades

\section{INTRODUÇÃO}

De acordo com o Conselho Nacional do Meio Ambiente - CONAMA, no uso das competências que the foram conferidas pela Lei ํㅜ 6.938, de 31 de agosto de 1981 e regulamentada pelo Decreto $\mathrm{n}^{\circ}$ 99.274, de 06 de junho de 1990, considerando a política urbana de pleno desenvolvimento da função social da cidade e da propriedade urbana, conforme disposto na Lei oㅜ 10.257, de 10 de julho de 2001.

É necessário programar as diretrizes que reduzam os impactos ambientais gerados pelos resíduos oriundos da construção civil. Com a nova Resolução do CONAMA no 448, de janeiro de 2012, alterando o dispositivo da Resolução no $307 / 2002$, em seu art. $1^{\circ}$ estabelece de fato as diretrizes, os critérios e os procedimentos para a gestão dos resíduos oriundos da construção civil, considerando alguns conceitos: segundo a Associação Brasileira de Normas Técnicas - ABNT em sua norma NBR - 10004 (2004) - relata "Resíduos Sólidos Classificação", os Resíduos da Construção Civil (RCC), também conhecido como Resíduos da Construção e Demolição (RCD) são em geral classificados como inertes (Classe II-B), uma vez que, quando submetidos a testes de solubilização, ou seja, ao entrar em contato com a água os mesmos não apresentam nenhum de seus componentes solúveis.

O gerenciamento e a administração desses resíduos é o que possibilita uma política ambiental e social mais ampla e mais eficaz. Devido a isto, a Engenharia Civil é a "vilã" do ambiente, seja pelo consumo excessivo dos recursos ambientais, modificação do meio ambiente por extração de recursos ou pelo excesso de geração de resíduos, ocasionando um quantitativo excessivo de entulhos nas cidades.

É com esse intuito que as políticas de gerenciamento de resíduos e de gestão integrada têm como objetivo alcançar, estabelecer e organizar a geração, a redução, a reutilização, a reciclagem e o destino final dos resíduos, permitindo o tratamento adequado dos mesmos. Dentro deste contexto e das políticas do meio 


\section{Revista Nacional de}

Gerenciamento de Cidades

edificação considerando as três fases da construção - Demolição, Escavação e Construção, são mostrados indicadores da geração de RCC de um projeto residencial com 20 pavimentos semienterrados a ser construído a uma profundidade de $1,5 \mathrm{~m}$, e a lâmina do prédio com $350 \mathrm{~m}^{2}$, com dois apartamentos por andar, e tendo em vista que no mesmo local onde o projeto vai ser executado já exista uma edificação com $400 \mathrm{~m}^{2}$ de área construída numa área total de $1.200 \mathrm{~m}^{2}$.

A tabela 1 mostra em seus indicadores a quantidade, em média, de resíduos que é gerado em função do produto final.

Tabela 1: Indicadores de Geração de RCC em uma Edificação

\begin{tabular}{cccc}
\hline FASE & RESÍDUOS GERADOS & $\begin{array}{c}\text { PRAZO } \\
\text { ESTIMADO }\end{array}$ & $\begin{array}{c}\text { INDICADOR DE } \\
\text { GERAÇÃO }\end{array}$ \\
\hline DEMOLIÇÃO & Classe A e C & $\begin{array}{c}\text { De } 10 \text { a } 30 \\
\text { dias }\end{array}$ & 800 a $1000 \mathrm{Kg} / \mathrm{m}^{2}{ }^{3}$ \\
ESCAVAÇÃO & Classe A & $\begin{array}{c}\text { De } 10 \text { a } 20 \\
\text { dias }\end{array}$ & 1300 a $1400 \mathrm{Kg} / \mathrm{m}^{2}{ }^{4}$ \\
CONSTRUÇÃO & Classe A, B, C e D & $\begin{array}{c}\text { De } 6 \text { a } 48 \\
\text { meses }\end{array}$ & $100 \mathrm{a} 150 \mathrm{Kg} / \mathrm{m}^{2}{ }^{5}$
\end{tabular}

Fonte: Gusmão (2008, p. 37).

De acordo com os dados demonstrados observamos que nas etapas de demolição e escavação em um período de tempo menor que 30 dias o quantitativo de resíduos gerados é superior a etapa de construção, tendo em vista o período da execução.

Percebe-se que planejamento é a palavra que resume bem construção civil, sinônimo de economia, tempo, racionalização de material e mão-de-obra, desenvolvimento, sustentabilidade e responsabilidade. "Planejamento deve ser feito para reduzir custos, evitando retrabalhos e mudanças do projeto já em execução,

\footnotetext{
${ }^{3}$ Área de construção;

${ }^{4}$ Volume da escavação;

${ }^{5}$ Área de construção.
} 
Revista Nacional de

Gerenciamento de Cidades

isso proporciona redução no tempo de execução e melhor qualidade" (MARTINS, 2012, p. 42).

O planejamento é uma gestão minuciosa dentro da obra que busca evitar desperdício e consequentemente diminuir os impactos ambientais. Segundo Martins (2012), o processo de gestão de resíduos abrange todas as etapas das obras, ou seja, vai desde a correta utilização dos materiais, evitando que desperdícios ocorram, até a reciclagem e correta destinação de todos os resíduos.

\subsection{Quantificação}

As obras residenciais ou comerciais que utilizam processos construtivos convencionais, ou seja, estrutura de concreto armado associada a vedações em alvenaria com blocos de concreto ou cerâmico geram entre 0,10 e $0,15 \mathrm{~m}^{3}$ de Resíduos da Construção Civil - RCC $/ \mathrm{m}^{2}$ de área construída (CARELI, 2014).

Segundo o mesmo autor, $50 \%$ desse volume se referem à alvenaria, concreto, argamassas e cerâmicas; 30\% madeira; $10 \%$ ao gesso; $7 \%$ ao papel, plástico e metais; e 3\% são constituídos de resíduos perigosos e outros resíduos não recicláveis, inclusive rejeitos, conforme podemos observar na figura abaixo (Figura 2).

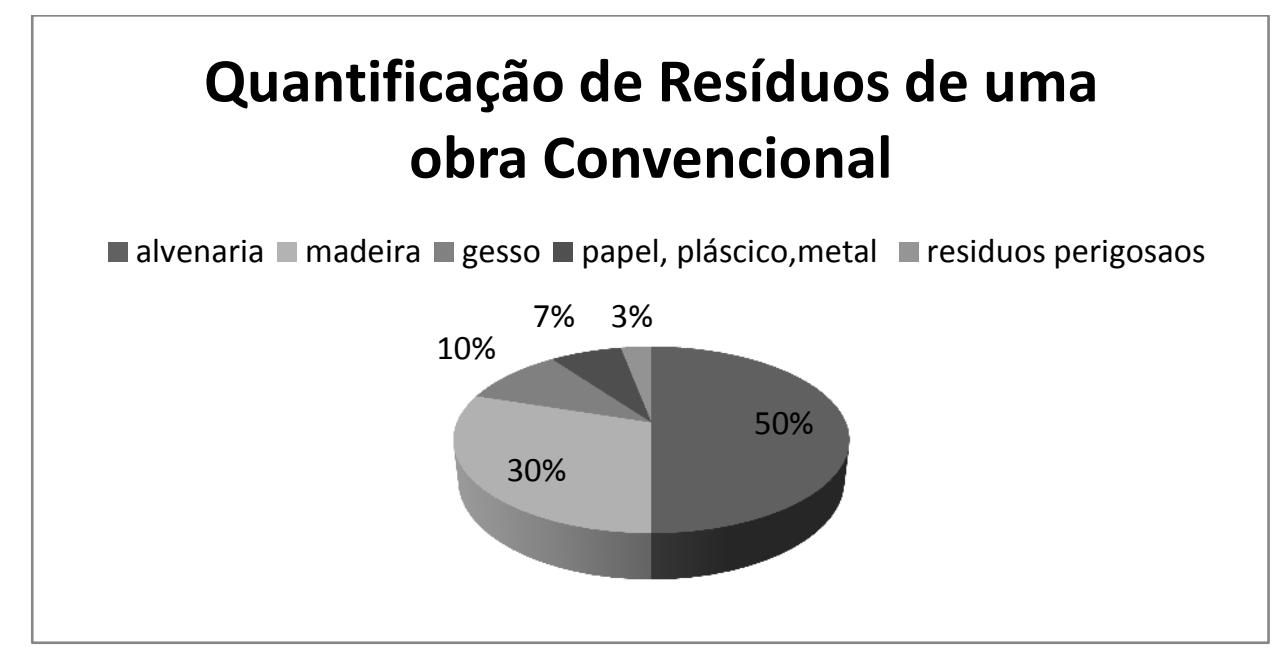

Figura 2: Quantificação de resíduos. Fonte: CARELI (2014), adaptação SILVA, R.C. (2015). 
Revista Nacional de

Gerenciamento de Cidades

Em outros valores podem ser estimados que a geração per capta de RCC no Brasil é 230-760 kg/ano, entretanto a mediana destes valores é $510 \mathrm{~kg} / \mathrm{hab} / \mathrm{ano}$, John \& Agopyan (2000, apud DELONGUI, 2011).

\title{
3.5 3R's da Sustentabilidade
}

Sabe-se que ações isoladas não minimizarão os problemas oriundos da geração de resíduos, uma forma de solucioná-los é a reciclagem quando possível e a criação de uma política sustentável unificada e ativa. Segundo Válquez (2001, apud GUSMÃO, 2008, p.17):

\begin{abstract}
A construção sustentável baseia-se na prevenção e redução dos resíduos pelo desenvolvimento de tecnologias limpas, na resolução e reciclagem dos materiais, e na coleta e deposição compromissada dos resíduos. Portanto, devem ser tomadas medidas que transformem os resíduos em recursos reaproveitáveis. No caso dos resíduos da construção civil - RCC, também chamados de resíduos de construção e demolição - RCD, quando são selecionados, graduados e limpos adequadamente, tornam-se um agregado secundário, cuja utilização, em função da origem e tratamento, pode se dar desde um aterro até um concreto estrutural com propriedades mecânicas plenamente satisfatórias.
\end{abstract}

É tomando como base essa política que o setor público, empresas privadas e sociedade civil devem atuar, buscando e programando metas que possibilite esse desenvolvimento. De acordo com Marques Neto (2005, apud GUSMÃO, 2008, p.26), a Política Nacional de Resíduos Sólidos (PNRS) considera em sua nova resolução objetivar e conjugar Planos Municipais de Gestão de Resíduos da Construção Civil e Planos Municipais de Gestão Integrada de Resíduos Sólidos. Esta resolução surgiu da urgente necessidade de solucionar problemas decorrentes da imensa geração dos RCC e de seus impactos ambientais, sociais e econômicos.

Uma vez que as Resoluções do CONAMA no 307/2002 e 448/2012 constituem grandes avanços entre as políticas de geração e o destino dos mesmos. É certo que algumas dificuldades precisam ser superadas para que resultados 
Revista Nacional de

Gerenciamento de Cidades

plenos possam ser atingidos, tendo em vista o longo período ocioso em que o setor da construção civil se manteve no tocante ou gerenciamento dos RCC (GUSMÃO, 2008, p. 29).

Com base na Cartilha de Gerenciamento de Resíduos Sólidos da Construção Civil (SINDUSCON-MG, 2005), o setor da construção civil deve traçar algumas metas dentro desse processo produtivo, objetivando minimizar os impactos ambientais, o não desperdício e a redução dos resíduos, desta forma, maximizando os lucros dentro da empresa que faz cumprir a política correta desse material. Dentro das diretrizes podem-se citar os 3R's da sustentabilidade:

- Reduzir e diminuir o volume de resíduos gerados;

- Reutilizar dentro da obra os materiais, elementos ou componentes que não precisem de tratamento especifico;

- Reciclar os materiais, transformando-os em matéria-prima para a produção de novos produtos.

A figura abaixo esquematiza essa relação entre processo produtivo, tratamento correto dos resíduos e destino final adequado dos rejeitos.

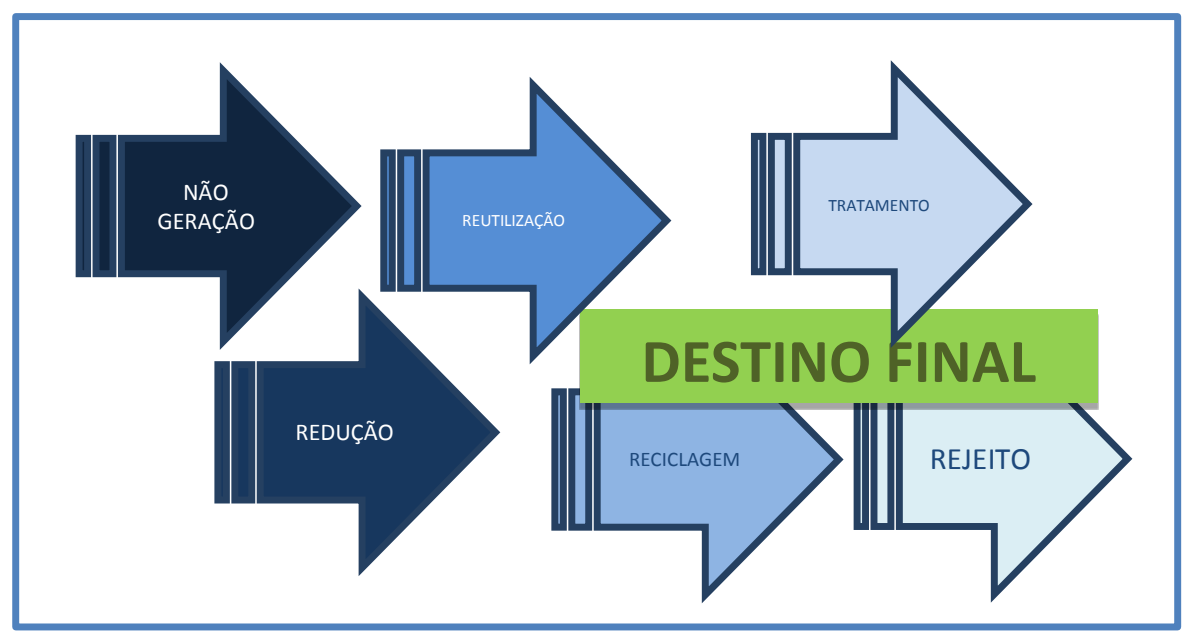

Figura 3: Fluxograma de Gestão de Resíduos da Construção Civil. Fonte: Adaptado do Art. 9o CONAMA (2012). 


\section{CONCLUSÕES}

Diante da problemática apresentada neste trabalho e tendo como referencial teórico vários autores e estudiosos da área buscou-se traçar um diagnóstico da realidade da Gestão de Resíduos da Construção Civil, no que se diz respeito à organização a geração, a redução, o transporte, a reutilização, a reciclagem e o destino final dos entulhos da construção civil, visando alcançar uma política de gerenciamento ambiental ativa e participativa dos órgãos privados e públicos.

$\mathrm{O}$ argumento para tal está relacionado com os impactos que a indústria da construção civil causa à sociedade em virtude de sua atividade, gerando e descartando seus resíduos em locais inadequados da cidade, contribuindo para a degradação do ambiente. O material gerado representa uma parcela significante do lixo urbano, fato este, que se faz necessária uma solução rápida e eficaz no gerenciamento desses materiais, minimizado os impactos com soluções precisas e tecnicamente corretas.

A elaboração de um projeto e a construção de um fluxograma de ações viabilizará um processo de destinação correta dos resíduos, seguindo a normatização da resolução CONAMA 307/2002, com enfoque nos princípios da preservação do meio ambiente.

Colocando em prática as ações propostas no projeto de gerenciamento o setor público e privado se beneficiará com o reconhecimento social diante da população, pois, trabalhar em uma empresa que preza pelos preceitos e valores do ambiente é garantia de redução de perdas e potencialização da geração de lucros. 
Revista Nacional de

Gerenciamento de Cidades

\section{LITERATURA CITADA}

BRASIL. Associação Brasileira de Normas Técnicas-ABNT/Norma Brasileira Regulamentadora-NBR 10004(2004). Dispõe da Classificação dos Resíduos Sólidos. ABNT NBR 10004:2004.

BRASIL. DA POLÍTICA NACIONAL DO MEIO AMBIENTE. LEI 6.938/1981 (LEI ORDINÁRIA) 31/08/1981. Dispõe sobre a Política Nacional do Meio Ambiente, seus fins e mecanismos de formulação e aplicação, e dá outras providências. Disponível em: http://www.planalto.gov.br/ccivil_03/leis//6938.htm. Acesso em 02/2015.

BRASIL. Decreto Federal no 7.404 de 23/12/2010. Estabelece Normas para Execução da Política Nacional de Resíduos Sólidos, de que trata a Lei $\mathbf{n}^{\circ}$ 12.305, de 2 de agosto de 2010. Disponível em: http://www.planalto.gov.br/ccivil_03/_ato 2007 2010/2010/Decreto/D7404.htm. Acesso em: 05/2014.

BRASIL. Decreto Federal no 99.274/1990. Regulamenta a Lei no 6.902, de 27 de abril de 1981, e a Lei no 6.938, de 31 de agosto de 1981, que dispõem, respectivamente sobre a criação de Estações Ecológicas e Áreas de Proteção Ambiental e sobre a Política Nacional do Meio Ambiente, e dá outras providências. Disponível em: http://www.planalto.gov.br/ccivil_03/decreto/antigos/d99274.htm. Acesso em 02/2015.

BRASIL. DOS INSTRUMENTOS DA POLÍTICA URBANA. LEI 10.257/2001. Regulamenta os arts. 182 e 183 da Constituição Federal, estabelece diretrizes gerais da política urbana e dá outras providências. Disponível em: http://www.camara.gov.br/sileg/integras/463822.pdf. Acesso em 02/2015.

BRASIL. Ministério do Meio Ambiente, Conselho Nacional do Meio Ambiente. Resolução 307, de 05 de julho de 2002. Art. 2으. Inciso I, Art. 3‥ Estabelece diretrizes, critérios e procedimentos para a gestão dos resíduos da construção civil. Diário Oficial da República Federativa do Brasil, Brasília, DF, no 136, 17 de julho de 2002. Seção 1, p. 95-96.

BRASIL. Ministério do Meio Ambiente, Conselho Nacional do Meio Ambiente. Resolução № 448, de 18 de janeiro de 2012. Estabelece diretrizes, critérios e procedimentos para a gestão dos resíduos da construção civil. Diário Oficial da República Federativa do Brasil, Brasília, DF, № 14, 19 de janeiro de 2012.

BRASIL. Ministério do Meio Ambiente, Conselho Nacional do Meio Ambiente - CONAMA. RESOLUÇÃO CONAMA ํㅜ 348, de 16 de agosto de 2004 Publicadas no DOU no 158, de 17 de agosto de 2004, Seção 1, página 70. Dispõe sobre gestão de resíduos e produtos perigosos. Disponível em: http://www.mma.gov.br/port/conama/legiabre.cfm?codlegi=449. Acesso em 02/2015.

BRASIL. Ministério do Meio Ambiente, Conselho Nacional do Meio Ambiente - CONAMA. RESOLUÇÃO CONAMA no 1 , de 23 de janeiro de 1986, Publicada no DOU, de 17 de fevereiro de 1986, Seção 1, páginas 2548-2549. Dispõe sobre Licenciamento Ambiental. Disponível em: http://www.mma.gov.br/port/conama/legiabre.cfm?codlegi=23. Acesso em 03/2015.

BRASIL. RESOLUÇÃO № 307, DEZ DE JULHO DE 2002. Publicada no DOU oㅜ 136, de 17/07/2002, pp. 95 e 96 - Alterada pelas Resoluções 348, de 2004, no 431, de 2011, e oํ 448/2012. 
